\title{
Maximum Inspiratory Pressure is a Discriminator of Pneumonia in Individuals With Spinal-Cord Injury
}

\author{
Anja M Raab MSc, Jörg Krebs PhD, Claudio Perret PhD, Franz Michel MD, \\ Maria TE Hopman MD PhD, and Gabi Mueller PhD
}

\begin{abstract}
BACKGROUND: Respiratory complications remain a major cause of mortality among individuals with spinal-cord injury (SCI). The present study investigated whether respiratory function is a discriminator of pneumonia in individuals with SCI and is aimed to determine the best predictive parameter. METHODS: This was a retrospective cohort study. Individuals with traumatic SCI, level $\mathrm{C} 3$ to T12, complete and incomplete lesions, were included. Data on respiratory function were extracted from medical records. The receiver operating characteristic curve was calculated for each parameter (forced vital capacity, $\mathrm{FEV}_{1}$, peak expiratory flow, and maximum inspiratory and expiratory pressure $\left[\mathbf{P}_{I \max }\right.$ and $\left.\mathbf{P}_{\text {Emax }}\right]$ ) to determine the discriminator with the largest area under the curve between individuals with and without pneumonia. RESULTS: Data of 307 subjects were analyzed. $P_{\text {Imax }}$ was identified as the best discriminator between individuals with and without pneumonia, both in motor complete (area under the curve $0.86,95 \% \mathrm{CI} 0.78-0.93, P<.001$ ) and incomplete individuals (area under the curve 1.0, 95\% CI 1.00-1.00, $P<.001$ ). In individuals with motor complete lesions, the threshold value for $P_{\text {Imax }}$ was $115 \%$ of the lesion-specific reference value (sensitivity $\mathbf{7 4 . 4 \%}$, specificity $\mathbf{8 3 . 4 \%}$ ). In motor incomplete individuals, the $P_{\text {Imax }}$ threshold value was $93.5 \mathrm{~cm} \mathrm{H}_{2} \mathrm{O}$ (sensitivity $100 \%$, specificity $100 \%$ ). CONCLUSIONS: $P_{\text {Imax }}$ is the best discriminator between spinal cord-injured individuals with versus those without pneumonia. Individuals with a $\mathbf{P}_{\text {Imax }}$ below threshold values are at risk of pneumonia. Key words: paraplegia; tetraplegia; respiratory complications; risk threshold; predictor; respiratory strength. [Respir Care 2016;61(12):1636-1643. () 2016 Daedalus Enterprises]
\end{abstract}

\section{Introduction}

As a result of respiratory muscle paralysis, tetraplegic individuals are prone to respiratory complications, which

Ms Raab and Drs Krebs and Mueller are affiliated with the Clinical Trial Unit, Dr Perret is affiliated with the Institute of Sports Medicine, and Dr Michel is affiliated with Ambulatory Services, Swiss Paraplegic Centre, Nottwil, Switzerland. Dr Hopman is affiliated with the Department of Physiology, Radboud University Nijmegen, Nijmegen, The Netherlands.

This work was supported by Wings for Life Grant WFL-CH-017/14. The authors have disclosed no conflicts of interest.

Supplementary material related to this paper is available at http:// www.rcjournal.com.

Dr Mueller presented a version of this paper at the 53rd International Spinal Cord Society Annual Scientific Meeting, held September 2-4, 2014, in Maastricht. Ms Raab presented a version of this paper at the 28th Annual Meeting of the Deutsche Medizinische Gesellschaft für Parapl- remain a major cause of mortality among individuals with chronic spinal-cord injury (SCI). ${ }^{1}$ In acute SCI, up to $80 \%$ of patients are affected by respiratory complications, ${ }^{2}$ and in $51 \%$ of these cases, pneumonia occurs. ${ }^{3}$ Many individuals with SCI who survive the acute hospitalization phase die within 6.2 y after discharge mainly as a result of cardiovascular and pulmonary diseases $(65 \%))^{4-6}$ The case fatality rate for pneumonia $(7.9 \%$ within $60 \mathrm{~d}$ ) is considerably greater in individuals with SCI compared with the

egie (DMGP), held June 25-27, 2015, in Kassel, Germany. Ms Raab also presented a version of this paper at the European Respiratory Society International Congress 2015, held September, 26-30, 2015, in Amsterdam, The Netherlands.

Correspondence: Anja M Raab MSc, Clinical Trial Unit, Swiss Paraplegic Centre, CH-6207 Nottwil, Switzerland. E-mail: anja.raab@paraplegie.ch.

DOI: $10.4187 /$ respcare. 04818 


\section{Discriminators for PNeUmonia In Spinal-CoRd InJury}

able-bodied population, and hospitalizations are more frequent with increasing age, tetraplegia, and the occurrence of comorbidities. ${ }^{7}$

From an economic point of view, individuals with SCI and respiratory complications have a significantly longer length of hospital stay compared with patients without respiratory complications ( $40.7 \mathrm{~d}$ vs $12.8 \mathrm{~d}) .{ }^{8}$ The number of respiratory complications experienced during the initial acute-care hospitalization is a more important determinant for stay and hospital costs than the level of injury in individuals with tetraplegia. ${ }^{9}$

To our knowledge, there are 3 studies on predictors of pneumonia in the SCI population. , $^{810,11}$ Two of these studies concentrated on factors of injury and shock severity ${ }^{10}$ or identified the level and completeness of injury as the fundamental clinical entity predicting respiratory complications. ${ }^{8}$ However, neither study investigated potentially modifiable factors. The third study focused on potentially modifiable factors, such as lung function, but did not cover respiratory muscle strength and did not define the inclusion of respiratory complications precisely. ${ }^{11}$ The purpose of the present study was therefore to investigate whether respiratory function, measured at an arbitrary point in time after onset of the SCI, can be used as a discriminator for pneumonia. We hypothesized that respiratory function parameters are able to discriminate between individuals with SCI and pneumonia and those without pneumonia.

\section{Methods}

\section{Design and Setting}

A retrospective cohort study was performed in a single SCI rehabilitation center. The study was approved by the ethics committee. We certify that all applicable institutional and governmental regulations concerning the ethical use of data of human volunteers were followed during the course of this research.

All patients in our center are informed about the potential retrospective use of their medical or personal data for research purposes in written form. All patients who reject the use of their medical or personal data for research purposes have been excluded from this research project.

\section{Study Population}

Male and female subjects with a primary diagnosis of traumatic SCI, American Spinal Injury Association Impairment Scale (AIS) A-D, motor level between C3 and T12, and age $\geq 18$ y were included. All data on pneumonia events, respiratory function, and personal or lesion characteristics were collected from the medical records.

Patients with progressive neurological diseases, such as multiple sclerosis or amyotrophic lateral sclerosis, were

\section{QUICK LOOK}

\section{Current knowledge}

Respiratory complications remain a major cause of mortality among individuals with spinal-cord injury. The present study investigated whether respiratory function is a discriminator of pneumonia in individuals with spinal-cord injury and aimed to determine the best predictive parameter.

\section{What this paper contributes to our knowledge}

Maximum inspiratory pressure $\left(\mathrm{P}_{\mathrm{Imax}}\right)$ was the best discriminator between spinal-cord injury individuals with and those without pneumonia. Therefore, individuals with $\mathrm{P}_{\text {Imax }}$ values below the reported threshold values may be at increased risk of pneumonia.

excluded as well as patients with mental disorders, acute or chronic respiratory diseases (except pneumonia), respiratory co-morbidities like sleep apnea and atelectasis, bronchodilators, or any other medication that could have influenced respiration at the time of assessment. If patients in our center suffer from respiratory problems like atelectasis or increased secretion, mechanical in-exsufflation and chest physiotherapy will be applied. The patients who need support for coughing receive manual cough assistance.

\section{Procedures}

Individuals who had suffered pneumonia from January 2010 to July 2014 were identified using the ICD-10 database of our center (Chapter X, Code J09 to J18.9). The following respiratory function data of subjects fulfilling the inclusion criteria were collected from the personal medical records: $\mathrm{FVC}, \mathrm{FEV}_{1}$, peak expiratory flow (PEF), and maximum inspiratory and expiratory muscle pressures $\left(\mathrm{P}_{\text {Imax }}\right.$ and $\left.\mathrm{P}_{\text {Emax }}\right)$. Since we hypothesize that pneumonia can influence the respiratory function parameters, no data were collected during the existence of pneumonia. The respiratory function data for subjects without pneumonia were extracted from the encrypted lung function database of our center. These data were filtered according to the inclusion and exclusion criteria.

\section{Statistical Analysis}

Demographic data are presented as mean \pm SD and median (interquartile range) or frequency. ${ }^{12}$ Respiratory function parameters were calculated as mean \pm SD. Normal distribution of the demographic data were tested using QQ-plots. Depending on the distribution of the data, an 
independent $t$ test or a Mann-Whitney $\mathrm{U}$ test was used to investigate group differences.

Subjects were divided into 2 groups: (1) SCI subjects with no diagnosis of pneumonia and (2) SCI subjects with the diagnosis of pneumonia. The cohort was further subdivided into subjects with motor complete (AIS A/B) and subjects with motor incomplete lesions (AIS C/D). Receiver operating characteristic (ROC) curves were calculated for evaluating the classification accuracy of the respiratory function variables for pneumonia. Individuals with motor complete and incomplete SCI were analyzed separately. For the individuals with motor complete SCI, all analyses were performed using the relative respiratory function values (percent of predicted according to personal and lesion characteristics). ${ }^{13}$ Using lesion-specific relative values of respiratory function is much more sensitive in this population. The lower the lesion level, the more respiratory muscles are innervated. Thus, the lesion level has a greater effect on respiratory function than sex or age in individuals with motor complete SCI. ${ }^{14}$ For the individuals with motor incomplete SCI, the absolute values were used for analysis because no lesion-specific prediction equations are available for this group of subjects.

The odds ratios, the likelihood ratios, and the positive and negative predictive values regarding the presence or absence of pneumonia were calculated for the discriminators with the largest area under the curve. The "pneumonia risk threshold" values for the best discriminators were determined by choosing the point with the lowest false positive and negative rate on the ROC.

Statistical significance was set at $P \leq .05$. All statistical analyses were performed using SPSS 18.0.3 (IBM, Armonk, New York). Additional details on the method for performing this study are provided in the supplementary materials at http://www.rcjournal.com.

\section{Results}

Overall, 110 patients with pneumonia and 237 without pneumonia were identified. From those subjects with pneumonia, 40 were excluded due to the following reasons: In 11 cases, invalid respiratory function measurements were available, 17 were diagnosed with progressive neurological diseases or chronic respiratory diseases, 10 did not fulfill the inclusion criteria (age and lesion level), and 2 had refused the retrospective use of their data. In total, 307 subjects were analyzed, 70 subjects $(23 \%)$ with pneumonia and 237 (77\%) without pneumonia. The demographic data are presented in Table 1.

\section{Subjects With Motor Complete Lesions, AIS A/B}

In the motor complete subgroup (AIS A/B), the relative $\mathrm{P}_{\text {Imax }}$ was the best discriminator between individuals with and without pneumonia (area under the curve $0.86,95 \% \mathrm{CI}$ $0.78-0.93, P<.001$ ) (Fig. 1 and Table 2). For the relative $\mathrm{P}_{\text {Imax }}$, a pneumonia risk threshold value of $115 \%$ of the lesion-specific reference value was identified with a sensitivity of $74.4 \%$ and a specificity of $83.4 \%$ (indicated as an arrow in Fig. 1). This means that the inspiratory strength needs to be $15 \%$ higher than the lesion-specific reference value. The odds of pneumonia in individuals with motor complete SCI and a relative $\mathrm{P}_{\text {Imax }}$ value $<115 \%$ were 16.1 (95\% CI 7.2-36.0, $P<.001$ ) times the odds in individuals with relative $\mathrm{P}_{\text {Imax }}$ values $\geq 115 \%$. In subjects with a $\mathrm{P}_{\text {Imax }}$ value $<115 \%$, the probability of suffering a pneumonia is $50 \%$ (positive predictive value). In contrast to subjects with a $\mathrm{P}_{\text {Imax }}$ value $>115 \%$, the probability of not suffering a pneumonia is $94 \%$ (negative predictive value). The positive predictive value represents the proportion of subjects with positive test results who were correctly diagnosed (true positives divided by all positives), and the negative predictive value represents the proportion of subjects with negative test results who were correctly diagnosed (true negatives divided by all negatives). ${ }^{15}$ The likelihood ratio includes both sensitivity and specificity and provides an estimate of how much a test result will change the odds of having a condition. ${ }^{15}$ The likelihood of subjects having pneumonia increased 4.6fold given a $\mathrm{P}_{\text {Imax }}<115 \%$. Conversely, the likelihood of having pneumonia decreased 0.29 -fold given a $\mathrm{P}_{\text {Imax }}$ $>115 \% .{ }^{15}$ The ROC curves and area-under-the-curve results for all other analyzed parameters are presented in Fig. 1 and Table 2.

The comparisons between individuals with and without pneumonia concerning lung function and respiratory muscle strength are presented in Fig. 2, A and B, respectively. A significant difference between motor complete SCI individuals with and those without pneumonia was observed for relative $\mathrm{FVC}(P<.001)$, relative $\mathrm{FEV}_{1}(P=.02)$, and relative $\mathrm{P}_{\operatorname{Imax}}(P<.001)$.

\section{Subjects With Motor Incomplete Lesions, AIS C/D}

For individuals with motor incomplete SCI (AIS C/D), $\mathrm{P}_{\text {Imax }}$ was also the best discriminator between individuals with and without pneumonia (area under the curve 1.00, 95\% CI 1.00-1.00, $P<.001$ ) (Fig. 3 and Table 2). A $\mathrm{P}_{\text {Imax }}$ risk threshold value of $93.5 \mathrm{~cm} \mathrm{H}_{2} \mathrm{O}$ was identified for individuals with AIS C/D lesions (sensitivity of $100 \%$, specificity of $100 \%$ ). The perfect discrimination between subjects with and those without pneumonia and, consequently, the false negative rate of 0 made the odds ratio calculation for $\mathrm{P}_{\mathrm{Imax}}$ impossible. The ROC curves and area-under-the-curve results for all other analyzed parameters are presented in Figure 1 and Table 2. In addition to the $\mathrm{P}_{\mathrm{Imax}}$, the expiratory parameters $\mathrm{FEV}_{1}, \mathrm{PEF}$, and $\mathrm{P}_{\mathrm{Emax}}$ were excellent discriminators between individuals with and 
Table 1. Characteristics of participants

\begin{tabular}{|c|c|c|c|}
\hline Characteristics & Individuals With Pneumonia $(n=70)$ & Individuals Without Pneumonia $(n=237)$ & $P$ \\
\hline Male, $n(\%)$ & $61(87)$ & $188(79)$ & \\
\hline Female, $n(\%)$ & $9(13)$ & $49(21)$ & \\
\hline Age AIS A/B, mean $\pm \mathrm{SD}$ y & $52.8 \pm 15.2$ & $46.0 \pm 13.9$ & $.01 \dagger$ \\
\hline Age AIS A/B, median (IQR) y & $53.0(42.0-65.0)$ & $46.0(36.0-56.0)$ & \\
\hline Age AIS C/D, mean $\pm \mathrm{SD}$ y & $53.2 \pm 17.7$ & $50.5 \pm 16.1$ & $.57 \dagger$ \\
\hline Age AIS C/D, median (IQR) y & $56.0(38.0-66.0)$ & $52.5(37.5-64.8)$ & \\
\hline Time post-injury AIS A/B, mean \pm SD y & $13.0 \pm 16.3$ & $13.2 \pm 12.7$ & .33 \$ \\
\hline Time post-injury AIS A/B, median (IQR) y & $2.0(0.5-27.0)$ & $9.0(1.0-22.0)$ & \\
\hline Time post-injury AIS C/D, mean \pm SD y & $0.9^{*}+ \pm 2.2$ & $8.2 \pm 12.4$ & $.01 \%$ \\
\hline Time post-injury AIS C/D, median (IQR) y & $0.1(0.1-0.3)$ & $3.0(0.1-11.8)$ & \\
\hline \multicolumn{4}{|l|}{ AIS grade, $n(\%)$} \\
\hline A & $34(49)$ & $143(60)$ & \\
\hline $\mathrm{B}$ & $12(17)$ & $50(21)$ & \\
\hline $\mathrm{C}$ & $15(21)$ & $25(11)$ & \\
\hline $\mathrm{D}$ & $9(13)$ & $19(8)$ & \\
\hline Height, mean $\pm \mathrm{SD} \mathrm{cm}$ & $175.3 \pm 9.0$ & $175.1 \pm 9.2$ & $.88 \dagger$ \\
\hline Height, median (IQR) cm & $174.5(170.0-182.0)$ & $175.0(169.0-180.0)$ & \\
\hline Weight, mean \pm SD kg & $72.2 \pm 14.7$ & $73.4 \pm 15.8$ & $.88 \dagger$ \\
\hline Weight, median (IQR) kg & $68.0(64.0-83.3)$ & $72.0(63.0-81.0)$ & \\
\hline \multicolumn{4}{|c|}{$\begin{array}{l}\text { All data belong to the date of the lung function measurement. } n=307 \text {. } \\
\dagger \text { Independent } t \text { test. } \\
+ \text { Mann-Whitney U test. } \\
\text { AIS = American Spinal Injury Association Impairment Scale } \\
\text { IQR = interquartile range }\end{array}$} \\
\hline
\end{tabular}

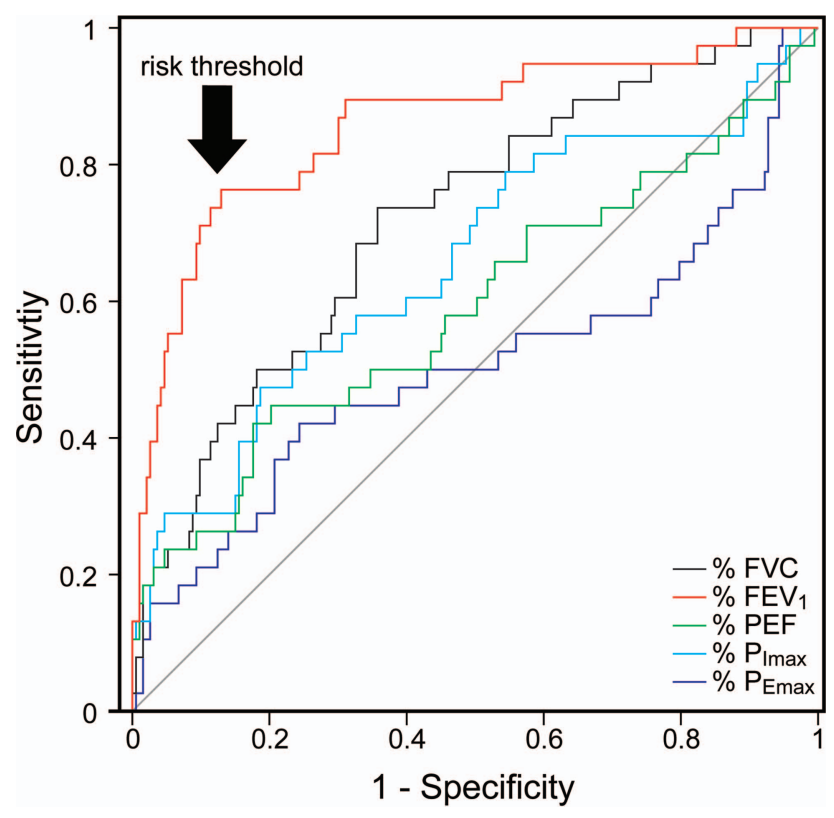

Fig. 1. Receiver operating characteristic curves for respiratory function parameters as discriminators for pneumonia in individuals with motor complete spinal-cord injury (American Spinal Injury Association Impairment Scale A/B).

without pneumonia. The risk threshold values were $3.1 \mathrm{~L}$ for $\mathrm{FEV}_{1}$ (sensitivity of $96 \%$, specificity of $100 \%$ ), $7.0 \mathrm{~L} / \mathrm{s}$ for PEF (sensitivity of $86 \%$, specificity of $100 \%$ ), and 83.5
Table 2. Results of the Receiver Operating Characteristics Analysis for All Assessed Respiratory Function Parameters

\begin{tabular}{|c|c|c|c|}
\hline $\begin{array}{l}\text { Respiratory Function } \\
\text { Parameter }\end{array}$ & $\begin{array}{l}\text { Area Under } \\
\text { the Curve }\end{array}$ & $P$ & $95 \% \mathrm{CI}$ \\
\hline \multicolumn{4}{|l|}{ AIS A/B $(n=232)$} \\
\hline $\mathrm{FVC}(\%)$ & 0.71 & $<.001$ & $0.62-0.80$ \\
\hline $\mathrm{FEV}_{1}(\%)$ & 0.64 & .006 & $0.53-0.75$ \\
\hline PEF $(\%)$ & 0.58 & .13 & $0.46-0.69$ \\
\hline $\mathrm{P}_{\operatorname{Imax}}(\%)$ & 0.86 & $<.001$ & $0.78-0.93$ \\
\hline $\mathrm{P}_{\text {Emax }}(\%)$ & 0.49 & .90 & $0.38-0.61$ \\
\hline \multicolumn{4}{|l|}{ AIS C/D $(n=63)$} \\
\hline FVC (L) & 0.74 & .002 & $0.61-0.87$ \\
\hline $\mathrm{FEV}_{1}(\mathrm{~L})$ & 0.99 & $<.001$ & $0.98-1.00$ \\
\hline PEF (L/s) & 0.93 & $<.001$ & $0.83-1.00$ \\
\hline $\mathrm{P}_{\operatorname{Imax}}\left(\mathrm{cm} \mathrm{H}_{2} \mathrm{O}\right)$ & 1.00 & $<.001$ & $1.00-1.00$ \\
\hline $\mathrm{P}_{\text {Emax }}\left(\mathrm{cm} \mathrm{H}_{2} \mathrm{O}\right)$ & 0.97 & $<.001$ & $0.92-1.00$ \\
\hline \multicolumn{4}{|c|}{$\begin{array}{l}\text { AIS }=\text { American Spinal Injury Association Impairment Scale } \\
\text { PEF }=\text { peak expiratory flow } \\
\mathrm{P}_{\text {Imax }}=\text { maximal inspiratory muscle pressure } \\
\mathrm{P}_{\text {Emax }}=\text { maximal expiratory muscle pressure }\end{array}$} \\
\hline
\end{tabular}

cm $\mathrm{H}_{2} \mathrm{O}$ for $\mathrm{P}_{\text {Emax }}$ (sensitivity of $91 \%$, specificity of $100 \%$ ). The comparisons between individuals with and those without pneumonia concerning lung function and respiratory muscle strength are presented in Figure 2, C and D, respectively. A significant difference between individuals with and those without pneumonia was observed for all 

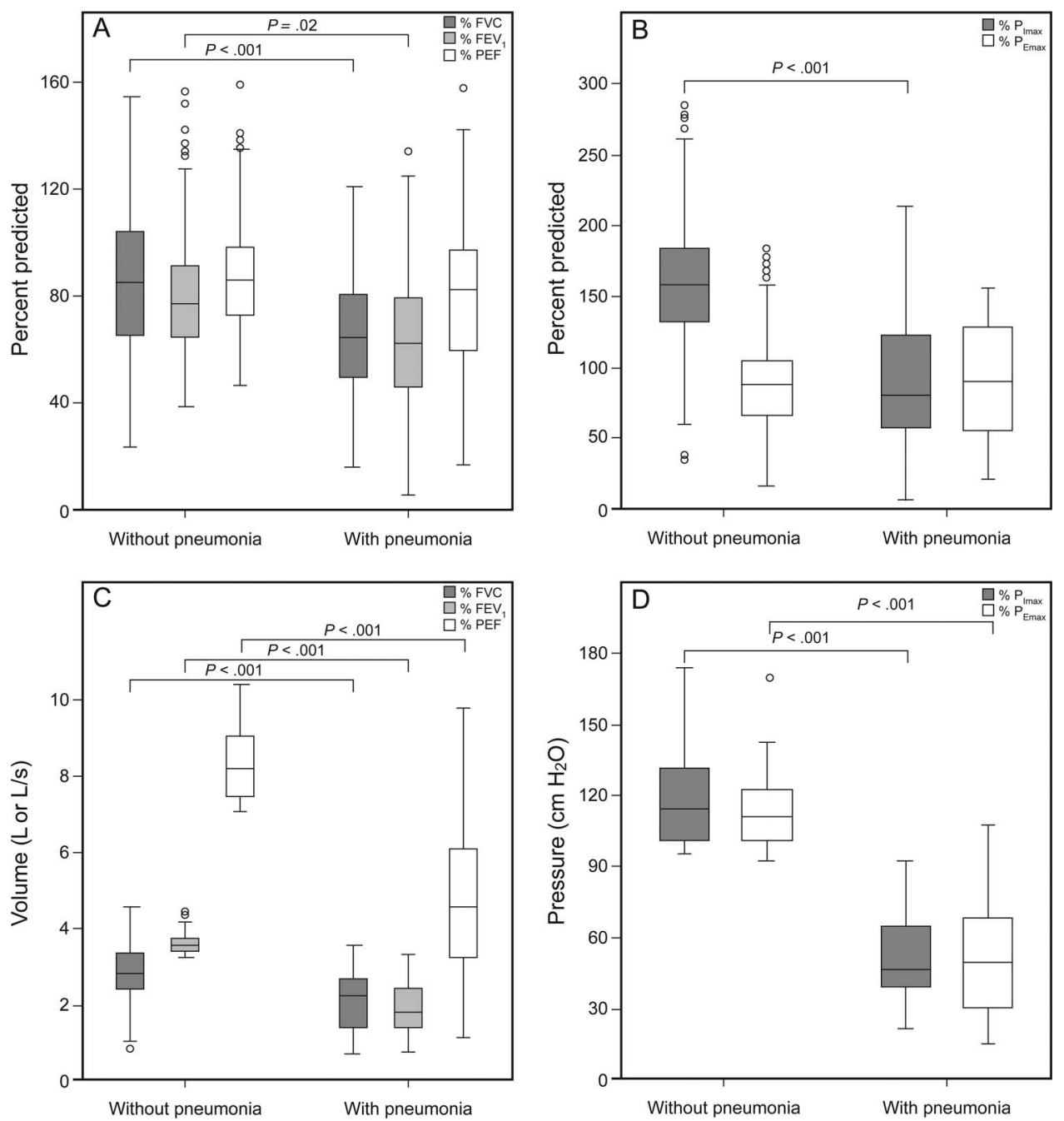

Fig. 2. A: Comparison of relative (\% predicted for spinal-cord injury, $\mathrm{SCl}$ ) respiratory function parameter values $\left(\mathrm{FVC}\right.$, FEV $\mathrm{B}_{1}$, and peak expiratory flow [PEF]) between motor complete SCI (American Spinal Injury Association Impairment Scale [AIS] A/B) individuals with and those without pneumonia. B: Comparison of relative (\% predicted for $\mathrm{SCl}$ ) respiratory muscle strength parameter values (maximum inspiratory muscle pressure $\left[\mathrm{P}_{\text {Imax }}\right]$ and maximum expiratory muscle pressure $\left[\mathrm{P}_{\text {Emax }}\right]$ ) between motor complete $\mathrm{SCl}(\mathrm{AIS} \mathrm{A} / \mathrm{B})$ individuals with and those without pneumonia. C: Comparison of absolute respiratory function parameter values (FVC, FEV 1 , and PEF) between motor incomplete SCI (AIS C/D) individuals with and those without pneumonia. D: Comparison of absolute respiratory muscle strength parameter values $\left(P_{\text {Imax }}\right.$ and $\left.P_{E \max }\right)$ between motor incomplete $S C I$ (AIS C/D) individuals with and those without pneumonia. Bottoms and tops of boxes are the first and third quartiles, and the horizontal line represents the median. Whiskers denote the lowest and the highest data points that are still within $1.5 \times$ the interquartile range from the lower and the upper quartile, respectively. Circles show outliers. $P \leq .050$.

respiratory function parameters, namely $\mathrm{FVC}(P<.001)$, $\operatorname{FEV}_{1}(P<.001)$, PEF $(P<.001), \mathrm{P}_{\operatorname{Imax}}(P<.001)$, and $\mathrm{P}_{\text {Emax }}(P<.001)$.

\section{Discussion}

$\mathrm{P}_{\text {Imax }}$ was found to be the best parameter to discriminate between SCI individuals with and those without pneumonia independent of injury severity. A $\mathrm{P}_{\mathrm{Imax}}$ threshold value of $115 \%$ of the lesion-specific reference value in motor complete individuals and $93.5 \mathrm{~cm} \mathrm{H}_{2} \mathrm{O}$ in motor incomplete individuals were identified.
In individuals with AIS C/D lesions, also the expiratory parameters $\mathrm{FEV}_{1}$, PEF, and $\mathrm{P}_{\mathrm{Emax}}$ were excellent discriminators between individuals with and those without pneumonia.

\section{Characteristics of Participants}

The $23 \%$ pneumonia rate in our representative sample lies in the middle of the reported range of $3-50 \%$ in the literature..$^{8,10,16-19}$ In the motor complete subgroup, individuals without pneumonia were significantly younger than those with pneumonia. This confirms the findings of ear- 


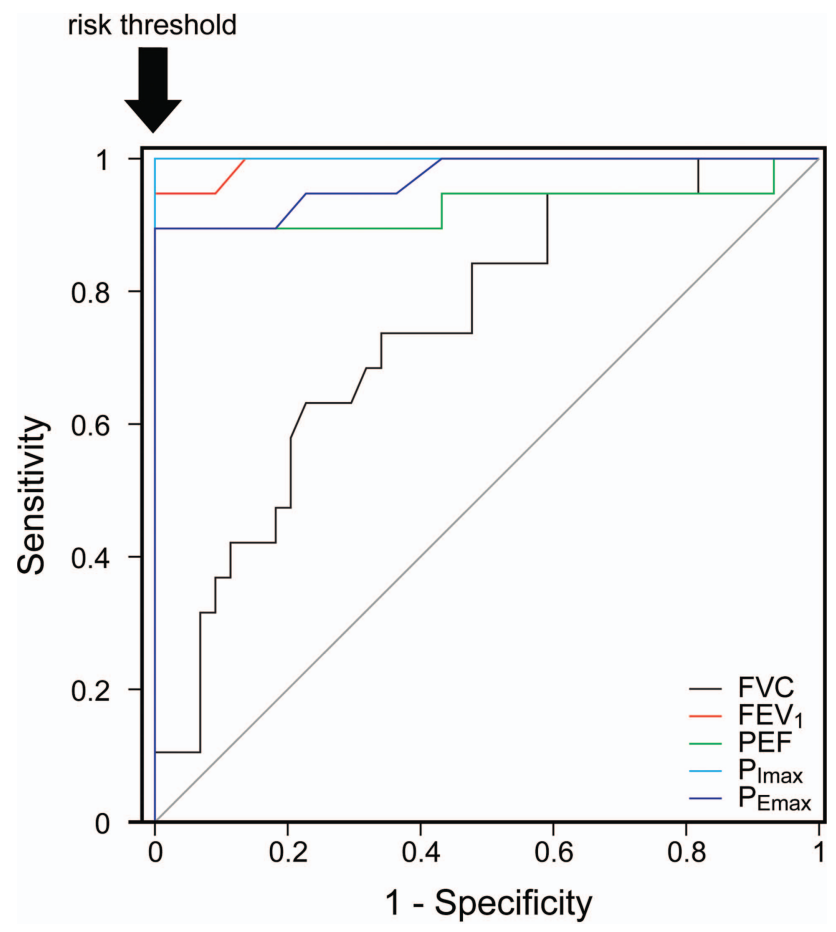

Fig. 3. Receiver operating characteristic curves for respiratory function parameters as discriminators for pneumonia in individuals with motor incomplete spinal-cord injury (American Spinal Injury Association Impairment Scale C/D).

lier studies, that the younger the patients are, the less prone they are to respiratory complications..$^{20,21}$ Individuals with motor incomplete SCI seem to suffer pneumonia significantly earlier after injury compared with individuals with motor complete SCI (Table 1). However, the respiratory function tests in individuals with motor incomplete lesions were mainly performed during in-patient rehabilitation; therefore, results of this group are only valid for subjects up to 6 months after injury. In individuals with motor complete SCI, the respiratory function tests ranged from the acute phase until years after in-patient rehabilitation. In the chronic phase of SCI, time after injury does not seem to have a significant association with respiratory complications. ${ }^{22,23}$

\section{Subjects With Motor Complete Lesions, AIS A/B}

As an example, the calculated absolute $\mathrm{P}_{\operatorname{Imax}}$ value of an average motor complete subject from our sample with a lesion level $\mathrm{C} 6-\mathrm{C} 8$ is about $78 \mathrm{~cm} \mathrm{H}_{2} \mathrm{O} .{ }^{13}$ Therefore, the relative $\mathrm{P}_{\text {Imax }}$ risk threshold value of $115 \%$ of the lesionspecific reference value in individuals with motor complete SCI seems to be greater in comparison with the values in preceding investigations $\left(51-66 \mathrm{~cm} \mathrm{H}_{2} \mathrm{O}\right) .^{23-25} \mathrm{In}$ subjects who suffered from pneumonia, inspiratory strength was significantly lower than in individuals without pneu- monia (Fig. 2B). However, expiratory strength did not differ between individuals with motor complete SCI and pneumonia and those without pneumonia (Fig. 2B). Complete lesions of the spinal cord are accompanied by paralysis of the abdominal muscles; therefore, the mainly passive process of expiration cannot be augmented by a forceful contraction of the abdominal muscles. ${ }^{26}$ However, inspiratory muscle strength may be even more important for an effective cough than expiratory muscle strength because stronger inspiratory muscles can cause a greater pre-cough inspiratory capacity. ${ }^{25}$ Weak inspiratory muscles reduce the ability for deep inspiration, which is followed by a restricted production and distribution of the substance surfactant in the lungs. Consequently, the peripheral airways can collapse. ${ }^{27}$ Therefore, inspiratory muscle pressure may be an important factor in the development of pneumonia.

\section{Subjects With Motor Incomplete Lesions, AIS C/D}

In the group with motor incomplete SCI, $\mathrm{P}_{\text {Imax }}$ was also identified as the best discriminator between individuals with and those without pneumonia with a sensitivity and specificity of $100 \%$. This means that all subjects who suffered from pneumonia had a $\mathrm{P}_{\text {Imax }}$ value $<93.5 \mathrm{~cm} \mathrm{H}_{2} \mathrm{O}$. Furthermore, $\mathrm{FEV}_{1}, \mathrm{PEF}$, and $\mathrm{P}_{\mathrm{Emax}}$ seem to be excellent discriminators between individuals with and those without pneumonia in individuals with motor incomplete SCI. Only FVC was a poor discriminator. This may have resulted from including subjects with decreased abdominal muscle and pelvic floor muscle tone, in whom the effect of gravity on the diaphragm cannot be compensated for in the sitting position. The abdominal muscles in general are regarded as expiratory muscles, although they also mechanically support the movement of inspiration by the diaphragm. ${ }^{28}$

The inspiratory and the expiratory muscle strength were significantly higher in subjects who had no pneumonia compared with those with pneumonia (Fig. 2D). The constant expiratory strength in those with pneumonia is in contrast to the results of the motor complete SCI individuals and may be explained by the maintained coordinated action of innervated expiratory muscles. ${ }^{14}$

In contrast to the motor complete SCI individuals, PEF was a good discriminator in motor incomplete SCI individuals. The absolute PEF values in incomplete SCI individuals with no pneumonia and those with pneumonia were 8.3 and $4.7 \mathrm{~L} / \mathrm{s}$, respectively $(P<.001)$ (Fig. $2 \mathrm{C})$. At least 5-6 L for PEF are necessary to produce an effective cough, ${ }^{29}$ and a minimum flow of $2.7 \mathrm{~L} / \mathrm{s}$ is essential to clear secretions ${ }^{30}$ and to prevent respiratory complications. ${ }^{31}$ 


\section{Discriminators for PNeUmonia In Spinal-CoRd InJury}

\section{Clinical Relevance}

The risk threshold values reported in this paper can be used to identify patients at increased risk of pneumonia. Patients with $\mathrm{P}_{\text {Imax }}$ values below the risk threshold values are recommended to train their inspiratory muscle strength to prevent pneumonia. Inspiratory muscle training is effective and is able to increase $\mathrm{P}_{\text {Imax }}$ by $10-25 \% .{ }^{32}$ At the beginning of an active rehabilitation, individuals with motor complete tetraplegia only achieve approximately 50 $\mathrm{cm} \mathrm{H}_{2} \mathrm{O} \mathrm{P}_{\text {Imax }}$ on average, whereas those with motor complete paraplegia can achieve approximately $70 \mathrm{~cm} \mathrm{H}_{2} \mathrm{O}$ $\mathrm{P}_{\text {Imax }}$ on average. ${ }^{33}$ Over time, $\mathrm{P}_{\text {Imax }}$ can increase by approximately $20 \mathrm{~cm} \mathrm{H}_{2} \mathrm{O}$ until $1 \mathrm{y}$ after starting in-patient rehabilitation. ${ }^{33}$ This training potential should be utilized to attain the high threshold values for $\mathrm{P}_{\text {Imax }}$ to reduce the risk of pneumonia. An intensive respiratory muscle training should start early after the injury and be a routine part of the initial rehabilitation program and also lifelong follow-up care in individuals with SCI.

Based on our results, inspiratory muscle training for SCI patients with $\mathrm{P}_{\text {Imax }}$ values above the risk threshold values does not seem to be necessary for pulmonary rehabilitation. $\mathrm{P}_{\text {Imax }}$ can be measured easily, quickly, and at low cost. Unfortunately, no guidelines exist regarding the frequency of lung function tests. Nonetheless, respiratory function should be assessed regularly for clinical monitoring, ${ }^{19}$ which may also motivate patients for respiratory muscle training. In addition to $\mathrm{P}_{\text {Imax }}$ measurements, also PEF, $\mathrm{FEV}_{1}$, or $\mathrm{P}_{\text {Emax }}$ can be used as reliable discriminators for individuals with incomplete SCI.

\section{Limitations}

This study was performed retrospectively. As a result, timing of respiratory function tests varied widely. Even with this temporal variation, the $\mathrm{P}_{\text {Imax }}$ parameter stands out as the best discriminator between those with and those without pneumonia.

Further, we do not have any details on the type of pneumonia as well as hospitalizations due to pneumonia and mortality. Using the ICD-10 code to identify patients with pneumonia may introduce selection bias. In our study, an independent person identified individuals with pneumonia using the ICD-10 database of our center.

Future research is needed to strengthen our current results from this retrospective analysis or to identify other modifiable predictors of pneumonia after SCI. In a next step, a large prospective multi-center cohort study should be performed in order to confirm or make the results of this analysis more precise and also to assess the type of pneumonia as well as hospitalizations and mortality.

\section{Conclusions}

$\mathrm{P}_{\text {Imax }}$ is the best discriminator between SCI individuals with and those without pneumonia. Therefore, individuals with $\mathrm{P}_{\text {Imax }}$ values below the reported threshold values may be at increased risk of pneumonia. In patients with motor complete lesions and $\mathrm{P}_{\mathrm{Imax}}$ values below the threshold values, inspiratory muscle training should be promoted in clinical practice to reduce the risk of pneumonia. In patients with motor incomplete lesions and accordingly completely or partly maintained expiratory muscle innervation, inspiratory as well as expiratory muscle training is recommended.

\section{ACKNOWLEDGMENTS}

We thank Dr Wolfram Schwegman for the data extraction from the ICD-10 database and Claudia Muri for the respiratory function measurements.

\section{REFERENCES}

1. Schilero GJ, Radulovic M, Wecht JM, Spungen AM, Bauman WA, Lesser M. A center's experience: pulmonary function in spinal cord injury. Lung 2014;192(3):339-346.

2. Tollefsen E, Fondenes O. Respiratory complications associated with spinal cord injury. Tidsskr Nor Laegeforen 2012;132(9):1111-1114.

3. Liebscher T, Niedeggen A, Estel B, Seidl RO. Airway complications in traumatic lower cervical spinal cord injury: a retrospective study. J Spinal Cord Med 2015;38(5):607-614.

4. Osterthun R, Post MW, van Asbeck FW, van Leeuwen CM, van Koppenhagen CF. Causes of death following spinal cord injury during inpatient rehabilitation and the first five years after discharge: a Dutch cohort study. Spinal Cord 2014;52(6):483-488.

5. Ahoniemi E, Pohjolainen T, Kautiainen H. Survival after spinal cord injury in Finland. J Rehabil Med 2011;43(6):481-485.

6. Lidal IB, Snekkevik H, Aamodt G, Hjeltnes N, Biering-Sørensen F, Stanghelle JK. Mortality after spinal cord injury in Norway. J Rehabil Med 2007;39(2):145-151.

7. Weaver FM, Smith B, Evans CT, Kurichi JE, Patel N, Kapur VK, Burns SP. Outcomes of outpatient visits for acute respiratory illness in veterans with spinal cord injuries and disorders. Am J Phys Med Rehabil 2006;85(9):718-726.

8. Aarabi B, Harrop JS, Tator CH, Alexander M, Dettori JR, Grossman RG, et al. Predictors of pulmonary complications in blunt traumatic spinal cord injury. J Neurosurg Spine 2012;17(1 Suppl):38-45.

9. Winslow C, Bode RK, Felton D, Chen D, Meyer PR Jr. Impact of respiratory complications on length of stay and hospital costs in acute cervical spine injury. Chest 2002;121(5):1548-1554.

10. Croce MA, Fabian TC, Waddle-Smith L, Maxwell RA. Identification of early predictors for post-traumatic pneumonia. Am Surg 2001; 67(2):105-110

11. Postma K, Bussmann JB, Haisma JA, van der Woude LH, Bergen MP, Stam HJ. Predicting respiratory infection one year after inpatient rehabilitation with pulmonary function measured at discharge in persons with spinal cord injury. J Rehabil Med 2009;41(9):729-733.

12. DeVivo MJ, Biering-Sørensen F, New P, Chen Y. Standardization of data analysis and reporting of results from the International Spinal Cord Injury Core Data Set. Spinal Cord 2011;49(5):596-599.

13. Mueller G, de Groot S, van der Woude LH, Perret C, Michel F, Hopman MT. Prediction models and development of an easy to use open-access 


\section{Discriminators for PNeUmonia In Spinal-CoRd InJury}

tool for measuring lung function of individuals with motor complete spinal cord injury. J Rehabil Med 2012;44(8):642-647.

14. Lanig IS, Peterson WP. The respiratory system in spinal cord injury. Phys Med Rehabil Clin N Am 2000;11(1):29-43, vii.

15. Attia J. Moving beyond sensitivity and specificity: using likelihood ratios to help interpret diagnostic tests. Aust Prescr 2003;26(5):111113. doi: 10.18773/austprescr.2003.082.

16. Liebscher T, Niedeggen A, Estel B, Seidl RO. Airway complications in traumatic lower cervical spinal cord injury: a retrospective study. J Spinal Cord Med 2015;38(5):607-614.

17. Rabadi MH, Mayanna SK, Vincent AS. Predictors of mortality in veterans with traumatic spinal cord injury. Spinal Cord 2013;51(10): 784-788.

18. Grossman RG, Frankowski RF, Burau KD, Toups EG, Crommett JW, Johnson MM, et al. Incidence and severity of acute complications after spinal cord injury. J Neurosurg Spine 2012;17(1 Suppl):119-128.

19. Berlly M, Shem K. Respiratory management during the first five days after spinal cord injury. J Spinal Cord Med 2007;30(4):309-318.

20. Reines HD, Harris RC. Pulmonary complications of acute spinal cord injuries. Neurosurgery 1987;21(2):193-196.

21. Lucke KT. Pulmonary management following acute SCI. J Neurosci Nurs 1998;30(2):91-104.

22. Stolzmann KL, Gagnon DR, Brown R, Tun CG, Garshick E. Risk factors for chest illness in chronic spinal cord injury: a prospective study. Am J Phys Med Rehabil 2010;89(7):576-583.

23. Postma K, Haisma JA, de Groot S, Hopman MT, Bergen MP, Stam HJ, Bussmann JB. Changes in pulmonary function during the early years after inpatient rehabilitation in persons with spinal cord injury: a prospective cohort study. Arch Phys Med Rehabil 2013;94(8): 1540-1546.
24. Mueller G, Hopman MT, Perret C. Comparison of respiratory muscle training methods in individuals with motor and sensory complete tetraplegia: a randomized controlled trial. J Rehabil Med 2013;45(3): 248-253.

25. Kang SW, Shin JC, Park CI, Moon JH, Rha DW, Cho DH. Relationship between inspiratory muscle strength and cough capacity in cervical spinal cord injured patients. Spinal Cord 2006;44(4):242248.

26. Ball PA. Critical care of spinal cord injury. Spine 2001;26(24 Suppl): S27-S30.

27. Schmidt-Nowara WW, Altman AR. Atelectasis and neuromuscular respiratory failure. Chest 1984;85(6):792-795.

28. Kelly BJ, Luce JM. The diagnosis and management of neuromuscular diseases causing respiratory failure. Chest 1991;99(6):14851494.

29. Fugl-Meyer AR. The respiratory system. In: Vinken PJ, Bruyn GW, editors. Handbook of Clinical Neurology. Vol. 26. New York: American Elsevier; 1976:335-349.

30. Kang SW, Bach JR. Maximum insufflation capacity. Chest 2000; 118(1):61-65.

31. Galeiras Vazquez R, Rascado Sedes P, Mourelo Farina M, Montoto Marques A, Ferreiro Velasco ME. Respiratory management in the patient with spinal cord injury. BioMed Res Int 2013;2013:168757. doi: 10.1155/2013/168757.

32. Tamplin J, Berlowitz DJ. A systematic review and meta-analysis of the effects of respiratory muscle training on pulmonary function in tetraplegia. Spinal Cord 2014;52(3):175-180.

33. Mueller G, de Groot S, van der Woude L, Hopman MT. Timecourses of lung function and respiratory muscle pressure generating capacity after spinal cord injury: a prospective cohort study. J Rehabil Med 2008;40(4):269-276. 